\title{
Supplement to Attributing the 2017 Bangladesh floods from meteorological and hydrological perspectives
}

Sjoukje Philip ${ }^{\text {KNMI }}$, Sarah Sparrow ${ }^{\mathrm{OeRC}}$, Sarah F. Kew ${ }^{\mathrm{KNMI}}$, Karin van der Wiel ${ }^{\mathrm{KNMI}}$, Niko Wanders ${ }^{\text {UU,CEE}}$, Roop Singh ${ }^{\text {RCRCCC }}$, Ahmadul Hassan ${ }^{\text {RCRCCC }}$, Khaled Mohammed ${ }^{\text {OeRC }}$, Hammad Javid $^{\mathrm{OeRC}}$, ECI , Karsten Haustein ${ }^{\mathrm{ECI}}$, Friederike E. L. Otto ${ }^{\mathrm{ECI}}$, Feyera Hirpa ${ }^{\mathrm{SoGE}}$, Ruksana Rimi $^{\text {ECI }}$, Saiful Islam ${ }^{\text {BUET }}$, David C. H. Wallom ${ }^{\text {OeRC, }}$, and Geert Jan van Oldenborgh ${ }^{\text {KNMI }}$

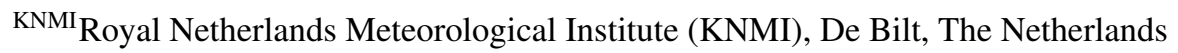

UUUtrecht University, Utrecht, The Netherlands

${ }_{\text {RCRCCC }}$ Red Cross Red Crescent Climate Centre, The Hague, the Netherlands

${ }^{\mathrm{OeRC}}$ Oxford e-Research Centre, Department of Engineering Science, University of Oxford, United Kingdom

${ }^{\text {SoGE }}$ School of Geography and the Environment, University of Oxford, United Kingdom

${ }^{\mathrm{CEE}}$ Department of Civil and Environmental engineering, Princeton University, Princeton, NJ, U.S.A.

Correspondence: Sjoukje Philip (philip@knmi.nl) and Geert Jan van Oldenborgh (oldenbor@knmi.nl)

\section{EC-Earth}

Fig. S1 shows the seasonal cycle of daily rainfall for both observations (CPC, ERA-int and GPCC) and the EC-Earth model. It shows that in the model, as expected, most precipitation falls in the months JJA, with a peak in July, like in observations, though the increase in precipitation is slightly steeper in June than it is in observations. The average amount of rainfall in these months is comparable to the observational datasets, with a maximum of around $10 \mathrm{~mm} / \mathrm{day}$. It is worth noting that CPC tends to underestimate the precipitation at higher elevations due to a lack of available station data.

\section{2 weather@home}

The annual cycle of 10-day running mean precipitation in the Brahmaputra basin from weather@ home Historical simulations is compared to CPC, GPCC and TRMM observational records in figure S2. Note TRMM is also included for reference but since data is not available post 2015 it is excluded from the rest of the analysis. Within the monsoon season the mean magnitude of precipitation within weather@home shows reasonable agreement with observational estimates, although the variability of precipitation in this period is too small. In the pre-monsoon season weather@home precipitation is too high and therefore the monsoon onset appears to occur too early within the model. Comparing the spatial agreement of JJAS mean precipitation (not shown) shows that, although model output is noisier, the magnitude and pattern of weather@home output agrees well with GPCC and CPC observations. 

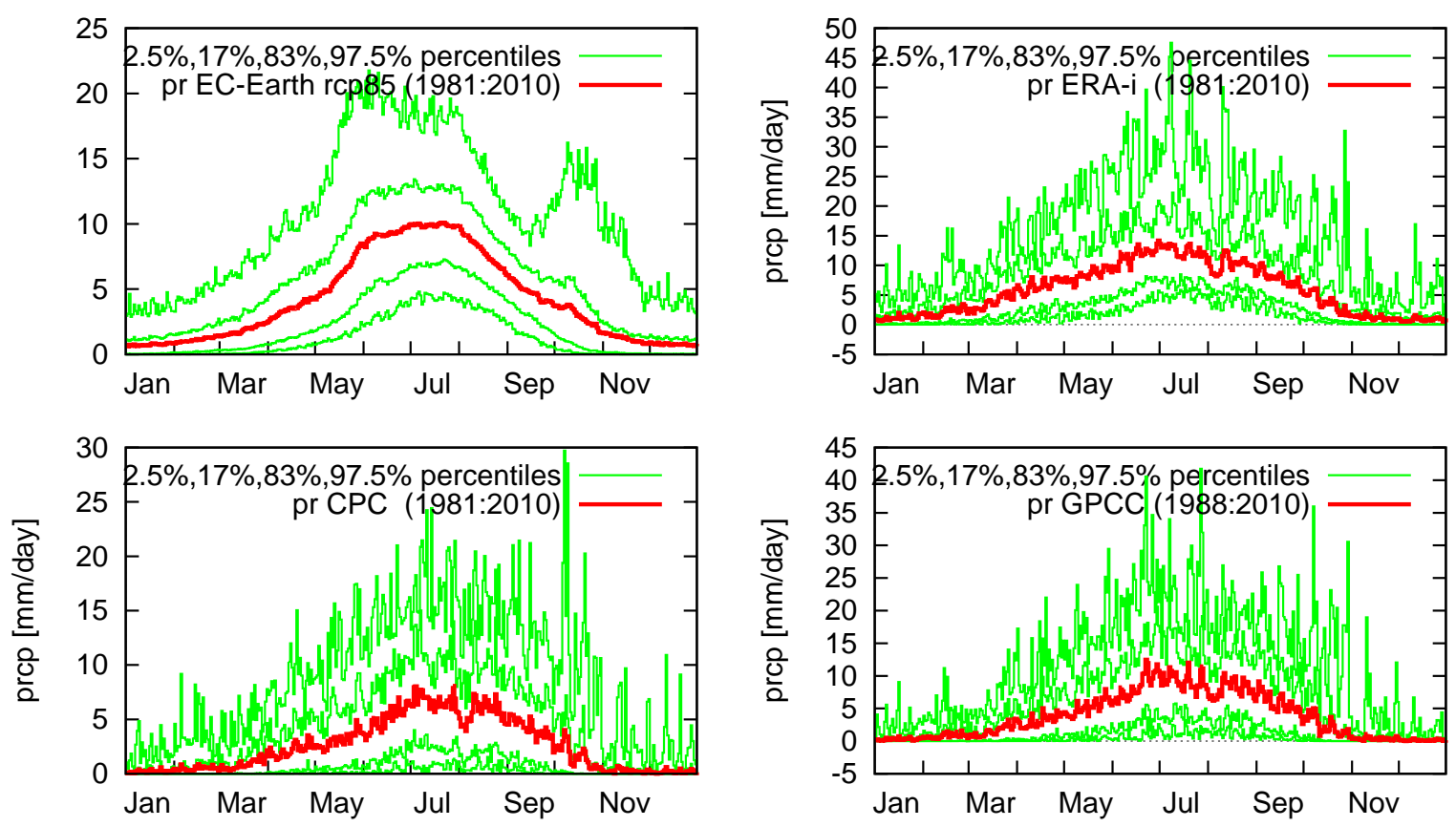

Figure S1. Seasonal cycle of EC-Earth (top left) and observational precipitation datasets wrt 1981-2010 (1988-2010 for GPCC). The red line shows the mean value, green lines show the $2.5,17,83$ and 97.5 percentiles.

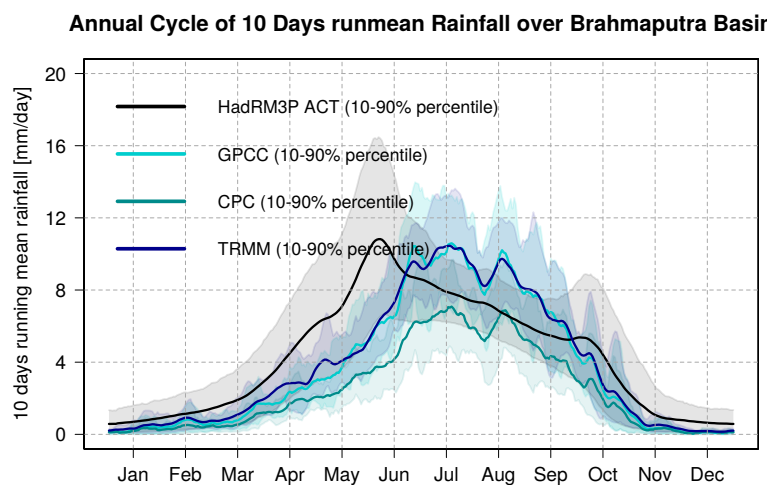

Figure S2. Annual cycle of 10-day running mean rainfall in the Brahmaputra region for weather@ home output and CPC, CPCC and TRMM datasets. 

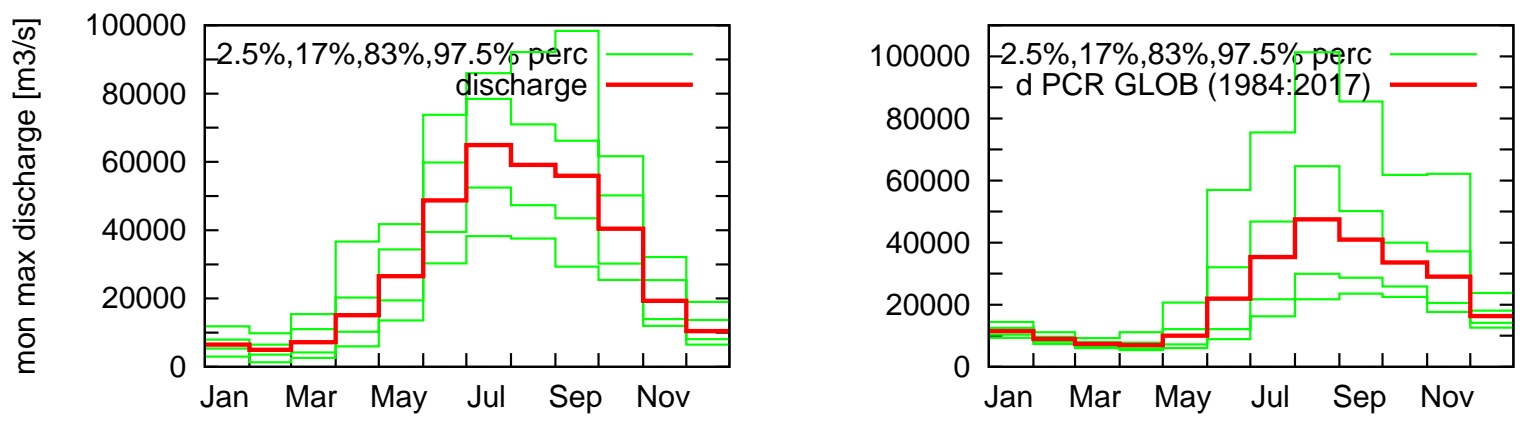

Figure S3. Annual cycle of monthly maximum discharge values for observations (left) and the PCR-GLOBWB model at Bahadurabad, calculated over all years available for observations (1984-2017). The red line shows the mean value, green lines show the 2.5, 17, 83 and 97.5 percentiles.

\section{PCR-GLOBWB}

PCR-GLOBWB calculates the vertical flow between soil layers and from the unsaturated to the saturated zone. It uses observed vegetation properties and land use dynamics to solve the water balance at the global scale for every $10 \times \mathrm{x} 10 \mathrm{~km}$ grid cell. The runoff from each location, flows along a topography driven drainage network to the outlet of the river basins. Over 6000 reservoirs and lakes are included in the drainage network to provide accurate simulations of river discharge in human modified river systems. Human water abstractions for irrigation, livestock, household and industry are included in the model. The model version has been extensively validated by Sutanudjaja et al. (2017) and showed a strong agreement between model and observed discharge. The model has been applied in many studies and has shown good performance with regard to simulations of floods (Winsemius et al., 2015), water demand (Wada et al., 2013), drought (Wanders and Wada, 2015a), seasonal teleconnections (Wanders and Wada, 2015b) and reservoir simulations (van Beek et al., 2011). The peak discharge value in the EC-Earth driven model is in August, which is slightly later than in observations but also in the months JAS that are analyzed in this study, see

5 Fig. S3.

\section{SWAT}

SWAT is a continuous-time hydrological model operating on a daily time step. SWAT is process based, semi-distributed and computationally efficient. In SWAT, the study area is divided into subbasins. These subbasins are then divided into different hydrological response units (HRU) which are the percentage of a subbasin area consisting of unique combined soil, land use and slope properties. After the HRUs are determined, the model calculates the water balance at each HRU using moisture and energy inputs provided by the user.

The water balance equation used in SWAT consists of daily precipitation, runoff, evapotranspiration, percolation and return flow. The simulated flows of all the HRUs in a subbasin are then added together and routed through channels, ponds and 


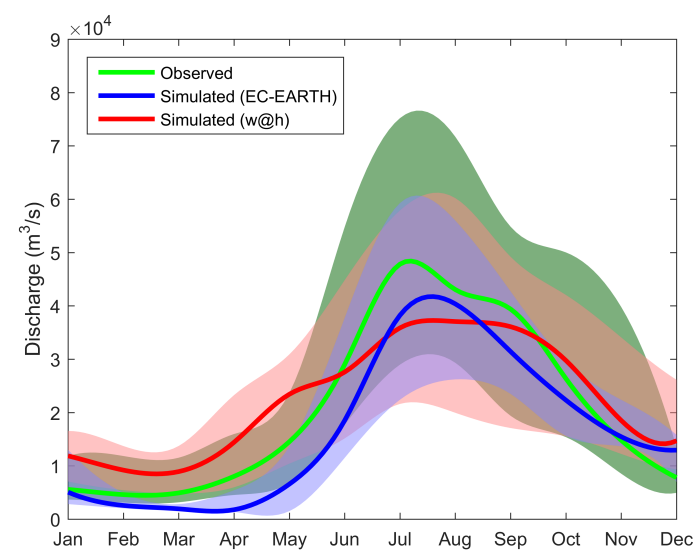

Figure S4. Comparison between monthly observed flows and SWAT simulated flows for both the EC-Earth and the w@h runs at Bahadurabad from 1986-2015.

reservoirs to the basin outlet. The methods available in SWAT for estimating surface runoff are the Soil Conservation Service (SCS) curve number method and the Green and Ampt infiltration method. Methods for estimating evapotranspiration are the Priestley-Taylor method, the Penman-Monteith method or the Hargreaves method. Methods for estimating flow routing in the river channels are the variable storage coefficient method and the Muskingum routing. Peak runoff is estimated using the modified rational formula. Percolation through each soil layer is estimated using storage routing techniques.

The annual cycle of observed and modelled discharges is shown in Fig. S4. When calibrated with EC-EARTH meteorological data the SWAT model tends to underestimate flows in almost all months of the year. When calibrated with weather@home meteorological data, the SWAT model tends to underestimate flows in the monsoon months while overestimating flows in the remaining months.

\section{Lisflood}

The routing scheme of Lisflood has been successfully used for flood forecasting at global scale in the Global Flood Awareness

5 System (GloFAS). GloFAS couples Lisflood routing scheme with the HTESSEL land surface module (Alfieri et al., 2013). The model can be run at a spatial resolution of $10 \mathrm{~km}$ to $100 \mathrm{~km}$ and at daily or hourly time steps which makes it suitable for both water balance and flood analysis studies (Knijff et al., 2010). The vertical fluxes, surface and subsurface runoff were simulated with the MOSES land surface scheme. The Met Office Surface Exchange System (MOSES) version 2.2 (Essery et al., 2001) is currently used to produce runoff at the Environmental Change Institute (ECI), University of Oxford for attribution studies.

The Nash and Sutcliffe (NS) efficiency of Lisflood model for the calibration and validation periods is 0.53 and 0.56 (Fig. S6).

The monthly validation graph shows that the Lisflood models is able to simulate the seasonality of rise in spring and summer flows correctly, see Fig. S5. The model underestimates the flows in summer. Lisflood simulated the decline in peak flows better 


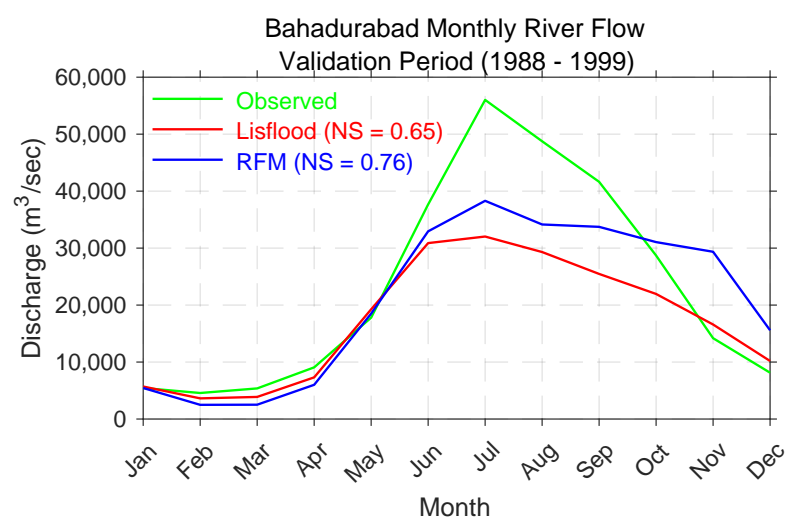

Figure S5. Mean monthly river flow observed at Bahadurabad gauging station and simulated with the Lisflood and RFM models. NS stands for Nash and Sutcliffe efficiency.
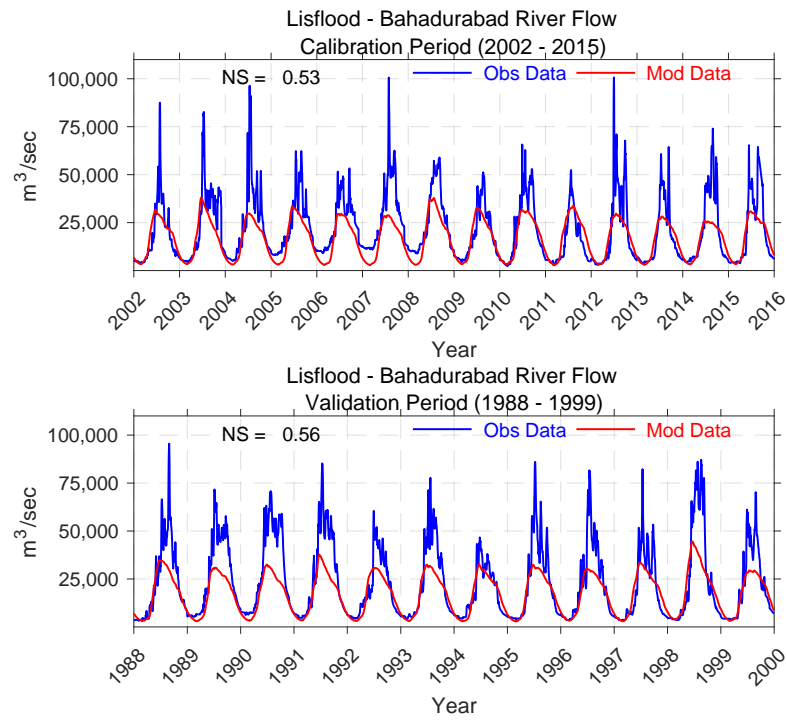

Figure S6. Daily observed and Lisflood simulated river flow at Bahadurabad gauging station.

than RFM in November and December. Underestimation of flows in summer is mainly because we used ensemble median for calibration of the model parameters which normalized the seasonal peaks.

\section{RFM}

The RFM routing is achieved by solving the kinematic wave equations separately for the two water sources (Dadson and Bell, 2010). The exchange of runoff between surface and subsurface components, usually at mountain slopes and in the channel network, is estimated as water depth through a return flow variable in the model (Bell et al., 2007). This routing scheme is 

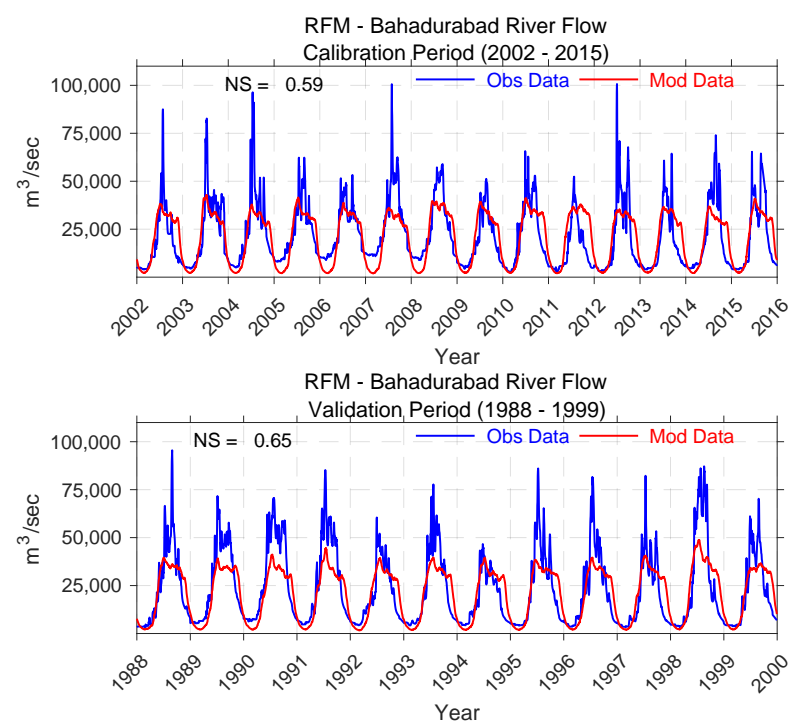

Figure S7. Daily observed and RFM simulated river flow at Bahadurabad gauging station.

currently being implemented in the Joint UK Land Environment Simulator (JULES, http://jules-lsm.github.io/vn5.0/namelists/ jules_rivers.nml.html).

RFM performed better than Lisflood with NS values of 0.59 and $0.65 \mathrm{NS}$ for the calibration and validation periods respec-

5 tively (Figure S7). The monthly validation graph shows that RFM is able to simulate the seasonality of rise in spring and summer flows correctly. The model underestimates the flows in summer but is slightly better than the Lisflood simulated river flow. Underestimation of flows in summer is mainly because we used ensemble median for calibration of the model parameters which normalized the seasonal peaks. 


\section{References}

Alfieri, L., Burek, P., Dutra, E., Krzeminski, B., Muraro, D., Thielen, J., and Pappenberger, F.: GloFAS; global ensemble streamflow forecasting and flood early warning, Hydrology and Earth System Sciences, 17, 1161-1175, https://doi.org/10.5194/hess-17-1161-2013, https://www.hydrol-earth-syst-sci.net/17/1161/2013/, 2013.

5 Bell, V., Kay, A., Jones, R., and Moore, R.: Development of a high resolution grid-based river flow model for use with regional climate model output, Hydrology and Earth System Sciences, 11, 532-549, http://nora.nerc.ac.uk/id/eprint/1654/, open Access paper. Click official URL for full-text., 2007.

Dadson, S. and Bell, V.: Comparison of Grid-2-Grid and TRIP runoff routing schemes, http://nora.nerc.ac.uk/10890/1/dadson_etal_2010_ g2gtrip.pdf, 2010.

Essery, R., Best, M., and Cox, P.: MOSES 2.2 Technical Documentation, Hadley Centre, Met Office, London Road, Bracknell, Berks R12 2SY, UK, http://jules.jchmr.org/sites/jules.jchmr.org/files/HCTN_30.pdf, 2001.

Knijff, J. M. V. D., Younis, J., and Roo, A. P. J. D.: LISFLOOD: a GIS-based distributed model for river basin scale water balance and flood simulation, International Journal of Geographical Information Science, 24, 189-212, https://doi.org/10.1080/13658810802549154, https://doi.org/10.1080/13658810802549154, 2010.

Sutanudjaja, E. H., van Beek, R., Wanders, N., Wada, Y., Bosmans, J. H. C., Drost, N., van der Ent, R. J., de Graaf, I. E. M., Hoch, J. M., de Jong, K., Karssenberg, D., López López, P., Peßenteiner, S., Schmitz, O., Straatsma, M. W., Vannametee, E., Wisser, D., and Bierkens, M. F. P.: PCR-GLOBWB 2: a 5 arc-minute global hydrological and water resources model, Geoscientific Model Development Discussions, 2017, 1-41, https://doi.org/10.5194/gmd-2017-288, https://www.geosci-model-dev-discuss.net/gmd-2017-288/, 2017.

van Beek, L. P. H., Wada, Y., and Bierkens, M. F. P.: Global monthly water stress: 1. Water balance and water availability, Water Resources Research, 47, https://doi.org/10.1029/2010WR009791, http://dx.doi.org/10.1029/2010WR009791, w07517, 2011.

Wada, Y., van Beek, L. P. H., Wanders, N., and Bierkens, M. F. P.: Human water consumption intensifies hydrological drought worldwide, Environmental Research Letters, 8, 034 036, http://stacks.iop.org/1748-9326/8/i=3/a=034036, 2013.

Wanders, N. and Wada, Y.: Human and climate impacts on the 21st century hydrological drought, Journal of Hydrology, 526, 208 220, https://doi.org/https://doi.org/10.1016/j.jhydrol.2014.10.047, http://www.sciencedirect.com/science/article/pii/S0022169414008427, drought processes, modeling, and mitigation, 2015a.

Wanders, N. and Wada, Y: Decadal predictability of river discharge with climate oscillations over the 20th and early 21st century, Geophysical Research Letters, 42, 10,689-10,695, https://doi.org/10.1002/2015GL066929, http://dx.doi.org/10.1002/2015GL066929, 2015GL066929, 2015b.

Winsemius, H. C., Aerts, J. C. J. H., van Beek, L. P. H., Bierkens, M. F. P., Bouwman, A., Jongman, B., Kwadijk, J. C. J., Ligtvoet, W., Lucas, P. L., van Vuuren, D. P., and Ward, P. J.: Global drivers of future river flood risk, Nature Climate Change, 6, 381 EP -, http://dx.doi.org/10.1038/nclimate2893, 2015. 